\title{
The Patras Blended Strategy Model for Deep and Meaningful Learning in Quality Life-Long Distance Education
}

\author{
Stylianos Mystakidis ${ }^{1,2}$, Eleni Berki ${ }^{2}$ and Juri Valtanen ${ }^{3}$ \\ ${ }^{1}$ University of Patras, Greece \\ ${ }^{2}$ University of Jyväskylä, Finland \\ ${ }^{3}$ Tampere University, Finland \\ smyst@upatras.gr \\ eleni.e.berki@jyu.fi \\ valtanenjuripetri@gmail.com \\ DOI: 10.34190/JEL.17.2.01
}

\begin{abstract}
Life-long learning is currently being embraced as a central process that could disrupt traditional educational paths. Apparently, the (ideal) type of learning often promoted is deep and meaningful learning, though it is not always required to be so. Deep learning goes beyond superficial knowledge assimilation of unlinked facts; it aims at developing deep disciplinary understanding, transformative knowledge, personal meaning, emotional intelligence, critical thinking, creativity and metacognitive skills. Meaningful learning occurs when learning is active, constructive, intentional, authentic, and cooperative. Technology enhanced teaching and learning methods should prove their potential to transform life-long learning provision and facilitate the achievement of deep and meaningful learning. In the context of distance education in life-long learning, one important challenge is the design of versatile quality assurance strategies for e-training. Based on the experiences in distance lifelong learning programmes in the University of Patras' Educational Center for Life-Long Learning (KEDIVIM) the authors present how the principles and attributes of deep and meaningful learning can be combined with project management in practice and be incorporated in an e-Learning quality strategy. We present i) the methods used to assess the quality of the e-Learning programmes, ii) key findings of the evaluation process and iii) first research evaluation results on the quality of learning. This research study on learning process quality was conducted by using an online questionnaire, which aimed at estimating the level of participants' satisfaction while using interactive learning methods such as collaborative learning. Some results of the evaluation indicate that the e-Learning quality strategy led to e-Learning programmes that used active learning methods to achieve high learners' satisfaction towards deep and meaningful learning.
\end{abstract}

Keywords: e-Learning, distance education, technology enhanced learning, life-long learning, deep and meaningful learning

\section{Introduction}

Lifelong learning is often embraced as a central transformative function that could disrupt the traditional and formal educational path of most professions. Learning is not just a prerequisite for employment; it is gradually becoming the actual core of work. This rather uncontrolled process is expected to affect $30-50 \%$ of today's jobs that could possibly be automated over the next 10 to 20 years (Peters, 2017). It seems that curricula in schools, colleges and universities and the way education itself is organized might need to adapt in order to enable young people and adults to acquire some skills and key competencies and update them throughout their life. In this contextual framework, the nature of learning that people are experiencing in various forms of education is of prime importance. In many instances of their lives people have been exposed to informationtransfer teaching and studying methods and activities that lead to rote, surface learning in form of memorization and raw assimilation of unlinked facts or procedures. In the era of the fourth industrial revolution a different kind of learning is encouraged to ensure employment (Gleason, 2018). Many new types of learning predominantly claim to consider a deeper disciplinary understanding combined with the essence of our humanity, our emotional intelligence, critical thinking, and creativity. This kind of learning is called deep and meaningful learning.

\section{The Distinctness of Deep and Meaningful Learning}

Deep and meaningful learning is the unification of two concepts and respective theories, deep learning and meaningful learning. The two concepts can be combined due to correspondences in their construction (Hay, 2007), as explained next.

Deep learning is the result of a deep approach to studying. This approach is characterized by the inherent interest in and active engagement with a discipline in a quest to grasp the underpinning principles and ISSN 1479-4403

CACPIL

Reference this paper: Mystakidis, S., Berki, E., and Valtanen, J., 2019. The Patras Blended Strategy Model for Deep and Meaningful Learning in Quality Life-Long Distance Education. The Electronic Journal of e-Learning, 17(2), pp. 66-78, available online at www.ejel.org 
associate it with previous knowledge. It encompasses the achievement of transformational knowledge, meaning and metacognitive skills (Marton and Säljö, 1976). Deep learning is positioned in the opposite spectrum of surface learning (or surface processing) as a quantitative increase of knowledge without reflection (Marton and Säljö, 1997).

Meaningful learning occurs when learning is active, constructive, intentional, authentic, and cooperative or relational (Jonassen, 2003). Meaningful learning builds on the interconnected attributes of teaching, studying and learning (Ausubel, 1961). Meaningful learning is associated with learning approaches such as discovery and problem solving resulting in the ability to identify the underlying structure and connect existing with new concepts (Howland, Jonassen and Marra, 2012). Short explanations for each feature follow:

- Active: Learning is an active mental process. This dimension signals the active participation of learners by interacting with content and the learning environment, and engaging with a subject matter so as to make a personal cognitive contribution.

- Constructive: Learners are expected to construct continuously their own meaning by interpreting and reflecting on observed phenomena and the results of their actions.

- Intentional: Learners are encouraged to exhibit individual ownership, agency, be self-directed, set goals consciously and commit emotionally.

- Authentic: Meaningful learning requires tasks linked to an authentic experience or simulated, realistic context so that they become personally significant and transferable.

- Cooperative/relational: Human learning is also a social process involving learners and teachers. Group collaboration and peer conversation occurs naturally in knowledge building communities. Also, the engaged, passionate teachers contribute significantly to the emotional involvement of learners (Howland, Jonassen and Marra, 2012).

\section{Deep and Meaningful Learning in Distance Education - Two Daunting Challenges}

Achieving deep and meaningful learning is a challenge in all modes of instruction -classroom-based, distance or blended-considering that the key stakeholder of the learning process is each learner with his/her unique features, characteristics, mental and emotional capacities. Thus, deep and meaningful learning requires considerable care, preparation, attention, mastery and effort. Deep learning is an even more daunting challenge in distance education. Distance education features predominantly flexible self-directed study in asynchronous mode. Even when learning combines synchronous teacher-lead or peer collaboration activities, learner isolation is an inherently inhibiting factor (Tyler-Smith, 2006). Researchers suggest using active and challenging learning activities, collaborative problem-solving tasks and emotional empowerment to promote deep learning in distance education (Hacker and Niederhauser, 2000).

Studies in the context of distance education and e-Learning connect deep learning with active learning, peer communication and collaboration (Morin, Thomas and Raafat, 2012) as well as high levels of teaching and social presence (Bangert, 2008). Meaningful learning in distance education is based on quality versus quantity of meaningful online interactions of learners with content, instructors and peers (Yoon, 2003). Meaningful interactions enable learners to enter the zone of proximal development (Jonassen et al., 1995; Lambropoulos et al., 2012). These interactions should be designed around authentic open-ended online activities that require complex knowledge construction tasks and provide opportunities for collaboration and reflection (Garrison and Cleveland-Innes, 2005; Woo and Reeves, 2007).

One often neglected factor in e-Learning is learners' emotions and motivation. Emotions are an inherent element of learning. Knowledge is associated with emotions and feelings. Feelings and emotional states evoked by internal or external factors can either facilitate or inhibit learning. Humans can have multiple goals and motives of different nature, extrinsic or intrinsic (Covington and Müeller, 2001). Learners with extrinsic goals engage learning for external incentives such as passing an exam or material rewards. Extrinsic motivation is associated with surface learning, anxiety and high drop-out rates (Rothes, Lemos and Gonçalves, 2017).

Learners with autonomous, intrinsic motives and goals are driven by the practice of learning itself. Intrinsic motivation is associated with deep learning, high performance and learning resilience (Zainuddin, 2018).

Thus, ignoring the importance of intrinsic motivation in distance education has resulted in high drop-out and attrition rates (Tyler-Smith, 2006). Education practitioners do not always know or are able to motivate, engage 
learners and integrate meaningful social activities (Mimirinis and Bhattacharya, 2007). This effect has been observed in a magnified scale in the Massive Open Online Courses (MOOCs) movement, where global participation in MOOCs rose to thousands and even hundreds of thousands but completion rates typically fluctuate around or below 10\% (Jordan, 2015).

\section{Distance Education and Life-Long Learning - A Convenient Combination}

The adoption of technology enhanced learning has often been designated as a critical success factor for education. European Union's Digital Agenda strategy encouraged the mainstreaming of e-Learning for all subjects in all levels of education in the national policies of all member states (European Commission, 2010; Hernández-Ros, 2012). Additionally, the EU's Digital Education Action Plan prioritizes the digital transformation of teaching and learning (European Commision, 2018). The ongoing development of new technologies and their applications influenced job market changes and trends and pinpointed the need for continuous professional development and update of skills and competencies. The latter is especially evidenced in the field of vocational education and training (European Commission, 2016a), where there has been created an emerging, dynamic field for distance Life-Long Learning (LLL). According to a recent study, distance education sector is rapidly growing and was recently estimated to represent the approximately $30 \%$ of the total education provision in Europe (Schneller and Holmberg, 2014). The European Centre for the Development of Vocational Training in its key policy priority "quality of VET delivery" also associates quality of learning directly with Technology-Enhanced Learning (CEDEFOP, 2016). In this context, LLL has been emphasized as a key policy objective in the Education \& Training 2020 strategic framework (European Commission, 2016b).

Traditional and emerging training providers have utilized distance education in order to offer life-long educational services to audiences far wider than those approached through traditional classroom-based method. Furthermore, online learning is considered as a critical component for their future long-term strategies by $70,8 \%$ US universities (OLC, 2014). This process could open vast opportunities for the re-creation of flexible, agile and customizable educational programmes in a cost-effective way.

Training providers face the multi-faceted challenge to transition into a new and often unknown operation mode considering all aspects that influence learning quality, such as: i) proper application of administrative procedures, ii) effective instructional and learning design, iii) sound use of media and materials, iv) the appropriate choice and utilization of technological applications and platforms, v) the certification of knowledge and skills, vi) the smart talent recruitment and onboarding, as well as vii) the optimal human resources management.

Several higher and adult education institutions with aligning strategic approaches and experience have undertaken the task to bridge education with LLL, continuous professional development, corporate training and vocational education and training by applying distance and blended learning methods. Next there is a presentation of the case study of the Educational Center for Life-Long Learning (KEDIVIM) in the University of Patras, Western Greece along with its initiatives for LLL programmes and strategies. This paper is a development of research presented in the Proceedings of the European Conference on e-Learning (Mystakidis et al., 2018a).

\section{Case study: The University of Patras distance life-long learning strategy}

The University of Patras has a long track record in the adoption of innovative action in education and learning, partly due to its strong technological component but also because of the progressive educational culture it embraces. In 1995 the University of Patras founded its own Centre for Vocational Education and Training (KEK). KEK notably operated in fields of excellence where the institute's personnel had demonstrated rich experience, national and international presence through scientific knowledge, research and professional expertise. The Centre implemented subsidized, national and European programmes, as well as self-financed actions along with open and free training courses. Following a new national higher education legislation, in 2018, KEK was transformed into the Educational Center for Life-Long Learning (KEDIVIM). Since 2014 KEK/KEDIVIM deployed the University of Patras' strategy project for Distance Life-Long Learning through the development of e-Learning courses and programmes. Three pillars have been selected as strategy foundations: Quality; Deep and Meaningful Learning; and Innovation. 
Quality is a rather 'elusive' concept with multiple dimensions and varying definitions depending on time, geographical location and contextual factors such as economy, policy and culture (Harvey, 2009). While there is no single, unanimous definition of quality, in the context of this paper the authors adopt the definition of quality as the degree to which a sum of endogenous characteristics satisfies a set of requirements (International Organization for Standardization, 2015) and is broadly accepted by (most of) the quality stakeholders (Berki, Georgiadou and Holcombe, 2004). In education, specifically, quality is associated with effectiveness, efficiency, equality, relativity and sustainability (Barrett et al., 2006) and the way these influence learners, instructors and other stakeholders.

Deep and Meaningful Learning encompasses the metacognitive level achievement of transformational knowledge, meaning and transferable skills (Marton and Säljö, 1976). It is directly linked to manifold thinking which is a balanced combination of caring, creative, critical and reflective thinking skills (Valtanen et al., 2008).

Innovation (in the form of creativity and critical thinking) is a dynamic priority for constant (both gradual and disruptive) change signals in distance education. Along with reflective and caring thinking that could point to the identification, experimentation, evaluation and adoption of novel methods, environments and tools for learning, quality improvement and facilitation of deep and meaningful learning can be realised in the quest for personalized lifelong learning.

According to various research studies' findings and reviews, distance education when designed, planned and implemented with an appropriate blend of pedagogical approaches, methods and technological means is equally effective and in some specific cases more effective than classroom-based instruction (Means et al., 2010; Siemens, Gasevic and Dawson, 2015).

For the achievement of the aforementioned three pillars, the University of Patras' e-Learning courses have been delivered using the blended learning model. Thus, the courses combine two or more of the following modes of learning: i) classroom instruction, ii) asynchronous e-Learning (flexible self- and group study, production of individual and team assignments and projects), iii) synchronous e-Learning (live meeting(s) with instructors and co-participants in a virtual environment); iv) social eLearning (informal, emergent learning).

More details are provided in e.g. Valtanen et al., 2013; Mystakidis, Berki and Valtanen, 2017; Mystakidis and Berki, 2018.

\subsection{The University of Patras model - A blended strategy for quality distance education}

Reviewing quality assurance approaches and strategies in education, one can identify approaches that focus on different aspects of quality. Some strategies focus on the system's internal structure considering internal stakeholders such as learners and instructors and examine whether specific measurements are consistently met. Other approaches assess the effect(s) of the system in question towards exterior recipients (e.g. customers, external stakeholders) and their satisfaction. Finally, alternative strategies correlate quality with the achievement or specific threshold or standards of excellence (Van Damme, 2000).

In the University of Patras' KEDIVIM along with its strategic focus on excellence, quality is not seen as a static object. It is perceived as a live, vibrant process that is first and foremost evaluated through the eye of the beholder (learner). For the purposes of quality assurance in educational or/and administrative processes we take into account the inputs, the outputs as well as the involved actors' feedback. Especially in the e-Learning courses, quality assurance guidelines and policies are shaped, informed and updated by international schemes, models, quality labels, and good field practices. Also the LLL courses operational life-cycle has been organized according to the elaborated Project Management methodology proposed by the Project Management Institute - PMI (Project Management Institute, 2008; Schwalbe, 2015).

International e-Learning Quality initiatives such as ECBCheck, EFQUEL, E-xcellence and Epprobate offer the opportunity to the e-Learning providers to assess internally or audit externally all aspects of e-Learning courses' provision and courseware (Vlachopoulos, 2016) such as a) Information about and organization of the programme, b) target audience orientation, c) course design and methodology, d) learners' motivation, e) collaborative learning, f) assignments \& learning progress, g) assessment \& tests, h) quality of content, i) media design, j) technology, k) evaluation \& review. 
The University of Patras' KEDIVIM blended strategy for quality e-Learning programmes is realized through the fostering of a mixed culture of quality attributes, self-evaluation and innovation components in the following ways: i) Active commitment to quality and excellence empowerment on and for all levels (executive/top, managerial/middle, operational/low), processes and personnel; ii) the establishment of flexible/agile frameworks with clear procedures for all the life-cycle stages of the programmes; iii) resolution to seek and willingness to accept feedback for improvement from various internal and external actors/stakeholders; iv) identification and dissemination of good practices, internally and externally.

More specifically, the University of Patras' blended quality LLL programmes model inspired by Morrison, Ross and Kemp (2006) includes the following processes in five stages:

- Stage I - Analysis, Initiation \& Preparation: Interested university faculty members or course leaders receive templates and guidelines to prepare the application of new LLL programmes in collaboration with KEDIVIM's personnel. Each submitted application is examined and approved by KEDIVIM's Council. One essential evaluation criterion is the programme's sustainability and correspondence to existing or anticipated learning or certification needs. Also, apart from subject-matter expertise and experience, an essential course leader selection criterion is experience in distance education and certification in professional e-Learning.

- Stage II - Design \& Development: In this phase, course leaders or instructors without experience in professional e-Learning are expected to prepare themselves by experiencing and participating in an eLearning trainers' crash-course. One outcome of the course is the elaborated design of their new LLL programme. In this process, one quality measure is safeguarding the selection, formulation and commitment to adequate and achievable learning outcomes with an effective mix of learning activities, usually in various, blended modes to achieve deep and meaningful learning. Simultaneously starts the flexible development of the learning environment, activities and materials for the new study programme. This can be produced usually by the members of the course teaching team with the guidance of KEDIVIM's professional staff or by external collaborators.

- Stage III - Marketing \& Implementation: KEDIVIM prepares relative communication material and, upon completion of Stage II, starts the marketing campaign of the new e-Learning program using a variety of media so as to reach the identified target audience. Here we highlight special considerations for sensitive population groups.

After the minimum number of participants is reached, starts the realisation of each course's iteration. Pilot iterations of courses are early encouraged. Special attention is given to the detailed preparation of all registered course participants to ensure smooth participation without any technological or emotional barriers.

- Stage IV - Evaluation: Internal or/and external assessors evaluate the programs in a formative and summative way, based on the Context, Input, Process, Product (CIPP) model (Stufflebeam, Madaus and Kellaghan, 2006). Course leaders and KEDIVIM's management receive the formative and summative evaluation results to improve aspects of current and subsequent course iterations.

\subsection{Principles for Deep and Meaningful Distance Life-Long Learning}

The strategic focus on quality, deep and meaningful learning and innovation formed important aspects of the stages of the model, as described above. More in depth information is provided next.

1. Analysis, Initiation \& Preparation: Instructors, tutors and trainers in the University of Patras' e-Learning courses are expected to exhibit advanced techno-pedagogical competences in distance teaching and learning according to the TPACK model (Koehler and Mishra, 2009). They are expected to identify the learners' needs and involve them in the curriculum focus of each course instance (Brinthaupt and Fisher, 2011). One basic goal is to combine elements and active learning techniques from three generations in distance education (Anderson and Dron, 2011) to contribute to the formation of a virtual community of inquiry and practice (Wenger, 1998). Course leaders and instructors have the choices to (a) participate in an experiential 8-week crash-course on e-Learning course design, development and teaching (Figure 1), (b) prepare learning activities, lesson plans and lead synchronous meetings with the direct collaborative involvement and presence of a coach, and (c) young trainers can seek support and informal guidance to improve learning from mentors, more experienced practitioners.

2. e-Learning Design \& Development: The five prescriptive characteristics of meaningful learning (active, constructive, intentional, authentic, and cooperative) were the overarching guidelines in Stage II - 
Course Design \& Development. More specific, instructors are encouraged to incorporate these principles in the instructional design of new proposed distance life-long learning programs. First, the achievement of learning outcomes is structured around related active learning activities. Passive learning and the delivery of knowledge in its final form are discouraged. Active learning activities model and enhance skills and behaviors that participants are expected to practice and transfer to their workplace. Another conscious effort is to incorporate spaced skills repetition so as to improve retention (Loftus, 1985). These activities should have an open dimension that allows the free, conversational interpretation of the studied discipline and the subsequent construction of meaningful artifacts or products that represent learners personally. The activities can be individual or collaborative. Collaboration and facilitated communication among peers are instrumental processes for the emergence and formation of a community of inquiry (Rourke and Kanuka, 2009). Moreover, effective e-Learning design for deep and meaningful learning should contain the element of choice. Learners should have some degree of freedom to choose intentionally a learning strategy combining different activities that reflect their personal interests and goals. Finally, a conscious effort is to enable authentic, realistic contexts in which these activities take place through techniques such as simulations and case studies.

3. Marketing \& Implementation: Each e-Learning programme has a preliminary period for the participants' onboarding process. During this period we take all the necessary steps to help learners' confidence and fluency with all learning tools, platforms and methods; first, they receive detailed instructions in text and video; second they are invited prior to the start of the program to attend to at least two test online meetings, where they have the opportunity to use all the available tools and prepare for all upcoming activities. In case of technical problems in that stage or during the course, they can contact technical support personnel via email, voice over IP systems or telephone.

During each LLL course iteration trainers are encouraged to consider the emotional aspect of deep learning by increasing participants' motivation in ways that reflect their personality and teaching style, especially in their written and oral communication.

4. Evaluation: An integral part of the quality assurance process is the systematic inquiry of the effectiveness of the course, the evaluation of distance LLL courses (Rossi, Lipsey and Freeman, 2004). For the evaluation we used the general quality indicators categories proposed by the European Union, that are: relevance, synergy, compatibility, effectiveness, efficiency, sustainability, impact, flexibility (European Commission, 1999). According to the CIPP model, we evaluate three axes, the supportive framework of the course (infrastructure, content, support, coordination), trainers (teaching performance), and course implementation (learning methods, results). The evaluation takes place during and after the end of courses. The principles of deep and meaningful learning are revisited after evaluation data are available to steer a program's upgrade. At the end of each course's iteration a final course report is produced that captures all essential information and evaluation findings. The report contains lessons learned during this course as described in the Closing process group in PMI's project management methodology (Project Management Institute, 2008). These lessons are entered as separate tagged entities in KEDIVIM's digital collaborative knowledge base, accessible to all personnel.

\section{Evaluation and Assessment Procedure: Research Questions and Methodology}

In order to assess the performance of the measurements towards excellence in KEDIVIM's e-Learning course design and delivery, we conducted a mixed research study. The study aimed at answering the following research question:

How were the participants' perceptions and experiences in the University of Patras Distance LLL programmes while using a blended quality strategy for teaching and learning?

The research was conducted in two stages. At the first stage, we combined data from the formative and summative evaluation of the University of Patras' LLL courses that KEDIVIM delivered from November 2016 to December 2018. Data collection instruments for each course's evaluation were: (i) anonymous online questionnaires that participants completed voluntarily; the formative in the middle of the course, and the summative after its implementation, (ii) structured and semi-structured observations for virtual, synchronous and face-to-face meetings. The formative and summative evaluation questionnaires consisted of closed and open-type questions, 82 and 41 items in total, respectively. They featured 39 and 27 quality indicators respectively (66 in total) on all aspects of the course's design and delivery. The quality indicators were formulated either as an overall course component (e.g. assignment feedback) or as an individual trait (e.g. 
motivation provided by a specific trainer) to be rated in a scale from 1 to 5 (none, low, moderate, very good, excellent). The formative questionnaire included also a section on participants' demographic data. The data was analyzed both quantitatively and qualitatively. Closed questions were analyzed statistically while openended questions were further processed utilizing content analysis' techniques (Cohen, Manion and Morrison, 2007).

We collected and combined data from 20 evaluated trainers' training courses in the field of Educational Sciences with 372 total participants by 16 training personnel members in various roles and with distinct or shared responsibilities. Seven of them had no previous experience as trainers in distance education. Each course featured at least 4 trainers and had a duration of 8 to 16 weeks. All courses were delivered using blended learning and had overall a completion rate of $85.48 \%$. In particular, we analyzed 202 responses from the formative and 176 responses from the summative assessment questionnaire, respectively. The majority of the participants in this study were female (70\%). As far as age is concerned, the two main categories were 25 34 years (54\%) and 35-44 (25\%). Concerning their level of education, almost all held a higher education degree (97\%) while $38 \%$ had an additional postgraduate degree. The participants had various backgrounds, the strongest representation being Humanities (22\%), Economy \& Management (21\%) and Natural Sciences (16\%).

The majority are at the beginning of their professional life, with zero (13\%) or less than ten years of professional experience (54\%). In this context, $66 \%$ currently work while $34 \%$ are unemployed, seeking to enter the job market. Their main motivation is the improvement of their place in the job market (starting a job, CV improvement, extra income, promotion). The full profile of the course participants are presented in Figure 1.

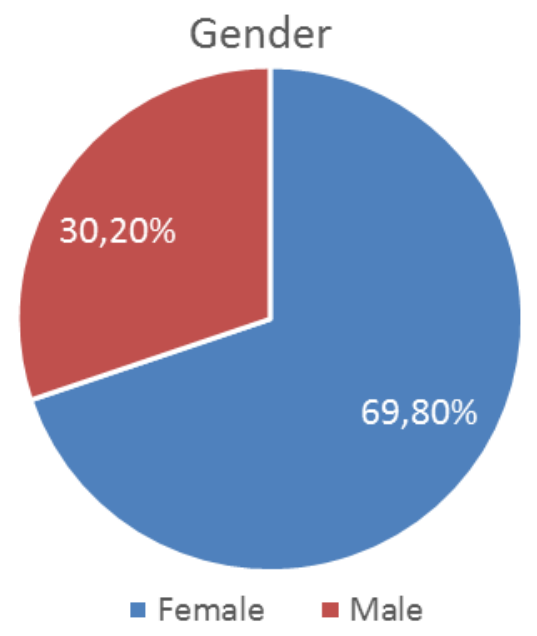

Work Experience

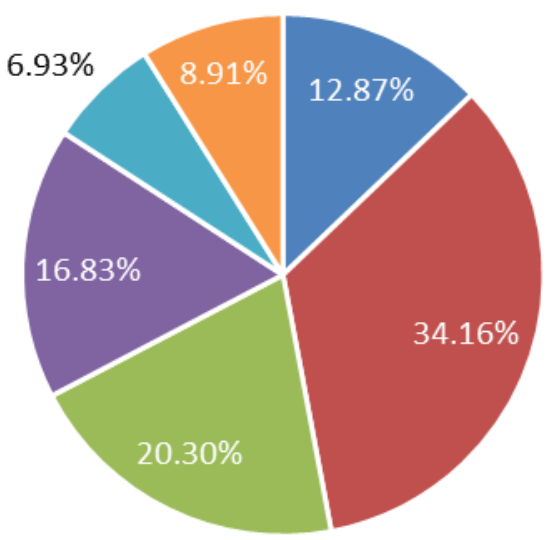

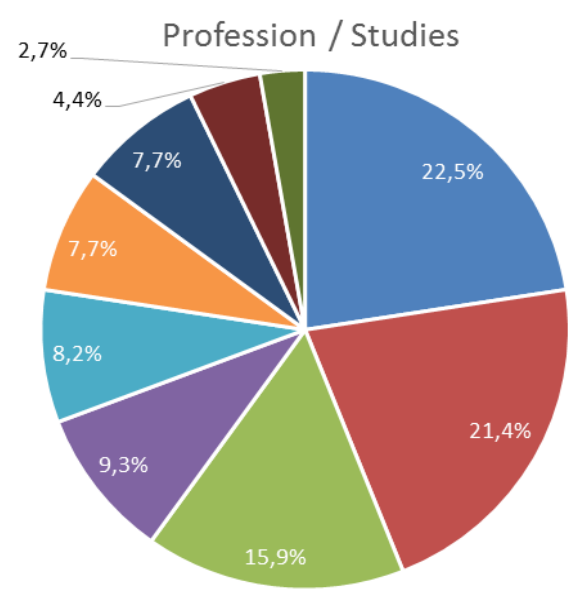

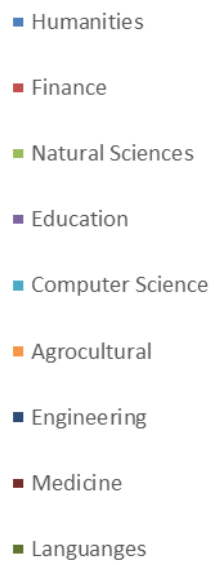

Age

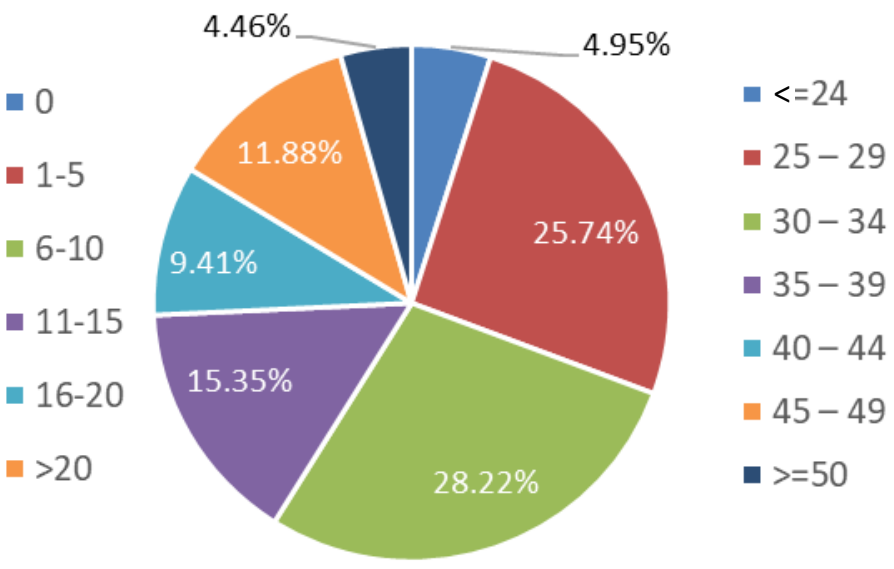

Figure 1: Profile of participants in University of Patras KEDIVIM LLL courses 
At the second stage, in collaboration with Hellenic Open University, we participated in an ongoing study on eLearning courses' participants' views on peer communication and collaborative learning for learning quality (Batsila, 2018). The study postulates that peer communication among learners and active learning methods such as social, collaborative learning are factors that can have a positive effect of the quality of distance LLL programmes (Ossiannilsson et al., 2015). The study used an anonymous online questionnaire consisting of three sections; (a) demographics, (b) general views on communication and collaborative learning, (c) inhibiting factors for collaborative learning. It had a total of 36 closed type questions using mainly a five-point Likert scale on the degree of agreement. The study took place between January and April 2018. KEDIVIM's participants from the above past courses were invited by email to participate in the survey in April 2018, i.e. 4 to 12 months after the end of the courses. 66 out of KEDIVIM's 318 contacted participants completed anonymously and voluntarily the online questionnaire. The survey received 157 responses in total. Early data analysis led to relevant findings supplementing the first stage. All questionnaires and responses in both phases were written in Greek language. The translation into English was carried out by one of the authors.

\section{Research Evaluation Outcomes}

\subsection{Formative and summative evaluation results}

\subsubsection{Statistical analysis}

Key findings on participants' satisfaction on quality from the evaluation process were the following:

1. All 20 LLL courses met the overall participants' expectations (cumulative Mean=4.39; SD=.753). Also when participants were invited to rate their overall learning experience in a scale from 0 to 10 , their responses were quite positive (cumulative Mean=8.6; $S D=1.339$ ).

2. 34 of 35 quality indicators concerning overall aspects of the course (Table 1 ) received very favourable ratings with average ratings ranging from 4.25 to 4.66 . Aspects with the highest satisfaction rates were live meetings, technical support, content, assignment usefulness, organization.

Table 1: Main quality indicators concerning the overall aspects of all courses

\begin{tabular}{|c|c|c|}
\hline Quality indicators & Mean & St. Dev. \\
\hline KEDIVIM's Organization & 4.42 & .648 \\
\hline Course Structure & 4.30 & .734 \\
\hline Learning Material & 4.46 & .681 \\
\hline Synchronous Learning & 4.47 & .683 \\
\hline Asynchronous Learning & 4.32 & .763 \\
\hline Assignments Usefulness & 4.48 & .631 \\
\hline Assignments Feedback & 4.30 & .882 \\
\hline Technical Support & 4.47 & .752 \\
\hline Administrative Support & 4.45 & .724 \\
\hline
\end{tabular}

The overall quality indicator that received the lowest rating was Time Allocation (Mean=3.69; SD=.941). The qualitative analysis of open questions revealed details in depth.

All 31 individual indicators concerning the trainers' performance (Table 2) revealed very high quality with means ranging from 4.48 to 4.91 .

Table 2: Main quality indicators on individual aspects of teaching performance in all courses

\begin{tabular}{|c|c|c|}
\hline Quality indicators & Mean & St. Dev. \\
\hline Synchronous Learning Trainer (SLT) Knowledge & 4.83 & .400 \\
\hline SLT Active Teaching & 4.79 & .504 \\
\hline SLT Trust & 4.78 & .522 \\
\hline SLT Motivation & 4.68 & .597 \\
\hline Asynchronous Learning Trainer (ASLT) Knowledge & 4.66 & .592 \\
\hline ASLT Active Teaching & 4.56 & .700 \\
\hline ASLT Trust & 4.54 & .691 \\
\hline ASLT Motivation & 4.50 & .720 \\
\hline
\end{tabular}

Observing the progress of quantitative results across time, we recorded a steady gradual improvement of metrics especially in trainers' performance indicators and the corresponding overall course quality indicators. In their first efforts with distance education, some trainers without prior experience, faced some difficulties, especially in the synchronous mode. This was evident also in the qualitative data. These trainers weren't always successful in their early efforts to establish a collaborative culture of active learning. Another difficulty 
they faced was an inability to manage effectively the limited time of synchronous meetings; sometimes it was hard to achieve a proper balance between meaningful open discussion among participants and off-topic wanderings. In the asynchronous mode, sometimes new e-trainers weren't punctual or effective in their feedback of assignments or at answering participants' questions. After appropriate timely feedback, guidance and mentoring, they were able to improve their practice or focus on their core strengths. As a result, critical comments on individual trainers decreased significantly and performance results of individual newcomer etrainers improved in each subsequent course they joined.

\subsubsection{Qualitative analysis}

Analyzing the responses to the open-ended items in the questionnaires, participants expressed their satisfaction for their learning progress and achievements as it was recorded in the ratings. Participants with experiences from similar courses praised the superiority of the KEDIVIM's courses both orally to the trainers and in their written comments. Opinions are unfolded below:

"The course in general offered me a plethora of new knowledge and helped me acquire new competences that I can apply in my professional activity, with some practice. The work done during meetings with trainers and through studying the educational material and completing learning assignments was very well organized and effective".

"I have no improvement suggestion. The program was very good and in comparison to courses from other universities e.g. (name), University of Patras' program is far superior in all aspects and especially in regards to microteaching".

The biggest challenge that was reported by some participants in certain programmes was the lack of time to participate in various aspects such as attendance to all synchronous meetings, study of the theoretical material and completion of mandatory assignments, in alignment with the survey finding (iii). Thus, they suggested longer course durations. This was an anticipated issue in LLL of adults who work and have additional roles and obligations. As this issue was detected early, we countered it with increased flexibility and personalization in course deadlines as well as positive reinforcement in the communication.

"The program should last longer with more frequent distance meetings of shorter duration so as have more time to study the educational material."

"The time allocation should be better. Time spans among virtual meetings and assignment deadlines could be longer so as to allow for better study of all units".

In certain programs some participants reported that the most troublesome element they encountered was the extensive content that made its study too demanding.

"I thought the volume of information was like a torrent, something that could be attributed to the fact that I have basic computer skills".

"As the course is aimed at adults with various roles and obligations, I believe the material is over compressed so as to be absorbed".

This is an indication of cognitive overload that inhibits deep and meaningful learning. In literature it is confirmed that when learners are overwhelmed, they tend to resort to surface approaches to complete the course in sketchy manner (Entwistle, Peterson and Elizabeth, 2000). Thus, course leaders received the recommendation to reduce educational material or workload.

Another finding was the total absence of technical problems mentioning and frustrations, a frequent phenomenon in e-Learning courses. This is consistent with the very high satisfaction rate with the technical support ( $A V=4.47 ; S D=.752$ ). This fact exposes the successful selection of suitable technological platforms, their smooth operation and, apparently, the effectiveness of the participants' preparation process.

\subsection{Quality evaluation findings - Learning process and outcomes}

The early analysis of the provisional data suggested that the delivery of the University of Patras' e-Learning programmes used successfully peer and active learning methods to achieve high learning quality, learner satisfaction, confidence and optimism. First, despite the considerable long period since course completion and the rudimentary communication effort, the response rate $(20.75 \%)$ reached levels significantly higher than the empirically reported averages in distance education programmes participants' surveys in Greece, which are 
around 5\% (Batsila, 2018). This could be interpreted as an indicator of appreciation and trust; they did not just complete a course and ran away. This observation is consistent with responses to question item 40 of the summative questionnaire; $78 \%$ would be interested in participating in future e-Learning courses provided by the University of Patras.

Moreover, $83.3 \%$ of KEDIVIM's respondents in the study confirmed that the communication among the participants was encouraged and facilitated. Further, $66.7 \%$ reported that collaborative learning took place during their course. In contrast, only $55 \%$ and $41.7 \%$ respondents from other Greek institutes and training providers reported the existence of peer communication and collaborative learning respectively.

This experience led to another interesting finding in parts B and C of the survey. The University of Patras courses' participants responded significantly higher (stronger degree of agreement) to all six "positive", "optimistic" statements in part B on the value, feasibility and importance of the aforementioned two factors for the quality of learning. Reversely, in part C, they responded consistently lower (weaker degree of agreement) to 21 out of 24 "negative" statements about problems and troublesome conditions that can hinder collaborative learning.

\section{Concluding Remarks, Implications for Practice, Limitations and Future Research}

A pilot evaluation study like the one presented herein revealed findings that contradict existing results from similar distance and LLL courses evaluation and unfolded rather surprising aspects of the learners' satisfaction.

Evaluation and data analysis from completed e-Learning courses revealed in accordance to preliminary results (Mystakidis et al., 2018) that the University of Patras' blended quality strategy had an overall positive effect.

All aspects of learning quality regarding design, development, content, personnel, media, platforms, organization, implementation and communication were confirmed. Teachers in both synchronous and asynchronous settings performed at a very high level considering the respective environments' affordances.

The participants expressed their high satisfaction in KEDIVIM's distance lifelong learning programmes that met their expectations.

The findings from this research study on learning quality support the claim that the perceived quality in the eyes of University of Patras' distance LLL program participants was high, possibly higher than experienced in other HE settings. This could also be attributed to the successful use of peer and active learning methods, and general commitment to other essential elements striving for realising deep and meaningful learning. The courses' participants (and survey's respondents) also appeared to be more confident and optimistic both by recognizing factors for learning quality improvement (learning process improvement, in particular) and not being discouraged by potential obstacles in peer collaboration. In summary, the issue of time management provided feedback for improvement while the live meetings, technical support (e.g. choice of suitable learning platforms) content assignment usefulness, overall organisation and trainers' performance make the Patras blended model outperform other models.

The provision of life-long learning and continuous education services is of growing importance for the information society and knowledge-based economy. Training providers need to find effective ways to meaningfully integrate technologies that enhance quality of education while at the same time guarantee the educators' commitment that can lead to deep and durable learning. The latter can be achieved by actively encouraging the emergence of a learner-centric involvement and pedagogic culture that aligns the assessment of learning through its outcomes in a more natural and pragmatic manner with 'liquid' curricula (Steils et al., 2015). For example, technology enhanced natural assessment methods focus on students' competences to synthesize knowledge and apply skills in contextual, realistic, simulated settings. This can be achieved by engaging learners in authentic experiences. This strategic priority needs to be nurtured and underpinned by a sustainable quality learning model. We argue that trainers should be at the heart of this model and be empowered to be the main motivating drivers of change towards digital transformation and innovation.

The empirical evidence of the current study should further be enriched in order to achieve a more compact and coherent Patras model. Undoubtedly, more survey results are needed from a representative number of 
courses with different duration and from all disciplines. In so doing the validation of the sustainability of the Patras model quality strategy could be objectified. Concerning the study's research design, one could point to the suitability of other research instruments such as focus groups or unstructured interviews which, in turn, could reveal different data and information; possibly also among participants from different ethnicity and culture. The authors also consider extending the current study in the direction of assessing the impact of the current, blended quality strategy on teaching effectiveness (by measuring learning outcomes), learning quality (by measuring learners experiences) and participants' overall satisfaction in the University of Patras distance LLL programmes. Additionally, the authors intend to measure the advancement of deep and meaningful learning in the course's and broader social context. In these contexts, the plan is to continue experimenting with e-Learning platforms, tools, applications, environments, techniques and methodologies that could provide the ground to found and realise learners' experiences for deep and meaningful learning.

\section{References}

Anderson, T. and Dron, J. (2011) 'Three generations of distance education pedagogy', International Review of Research in Open and Distance Learning, 12, pp. 80-97.

Ausubel, D. P. (1961) 'In Defense of Verbal Learning', Educational Theory. doi: 10.1111/j.1741-5446.1961.tb00038.x.

Bangert, A. (2008) 'The influence of social presence and teaching presence on the quality of online critical inquiry', Journal of Computing in Higher Education. Springer US, 20(1), pp. 34-61. doi: 10.1007/BF03033431.

Barrett, A. M. et al. (2006) The Concept of Quality in Education: A Review of The 'International' Literature on The Concept of Quality in Education, EdQual Working Paper.

Batsila, A. (2018) Communication and collaborative learning in quality assurance of online initial and continuing vocational education and training: European policy and the learners' perspective. Hellenic Open University.

Berki, E., Georgiadou, E. and Holcombe, M. (2004) 'Requirements engineering and process modelling in software quality management - Towards a generic process metamodel', Software Quality Journal, 12, pp. 265-283. doi: 10.1023/B:SQJO.0000034711.87241.fO.

Brinthaupt, T. and Fisher, L. (2011) 'What the best online teachers should do', ... and Teaching, 7(4), pp. 515-524. Available at: http://jolt.merlot.org/vol7no4/brinthaupt_1211.htm.

CEDEFOP (2016) Outcomes of the seminar 'learning providers and the quality of learning delivery'. Available at: http://www.cedefop.europa.eu/en/news-and-press/news/outcomes-seminar-learning-providers-and-quality-learningdelivery (Accessed: 29 April 2018).

Cohen, L., Manion, L. and Morrison, K. (2007) Research Methods in Education. 6th edn, Education. 6th edn. doi: 10.1111/j.1467-8527.2007.00388_4.x.

Covington, M. V. and Müeller, K. J. (2001) 'Intrinsic Versus Extrinsic Motivation: An Approach/Avoidance Reformulation', Educational Psychology Review. Kluwer Academic Publishers, 13(2), pp. 157-176. doi: 10.1023/A:1009009219144.

Van Damme, D. (2000) 'Internationalization and quality assurance: Towards worldwide accreditation?', European Journal for Education Law \& Policy, 4(1), p. 1. doi: 10.1023/a:1009994906190.

Entwistle, N., Peterson, J. and Elizabeth, R. (2000) 'Promoting deep learning through teaching and assessment: conceptual frameworks and educational contexts', Teaching and Learning Research Programme Annual Conference. doi: 10.18865/ed.25.3.321.

European Commision (2018) Digital Education Action Plan. Available at: https://ec.europa.eu/education/sites/education/files/digital-education-action-plan.pdf (Accessed: 28 April 2018).

European Commission (1999) MEANS collection: evaluating socio-economic programmes. Office for Official Publications of the European Communities (EC structural funds). Available at: https://books.google.gr/books?id=ahuptAEACAAJ.

European Commission (2010) A Digital Agenda for Europe, Communication. doi: COM(2010)245 final.

European Commission (2016a) New Skills Agenda for Europe. Available at: http://eur-lex.europa.eu/legalcontent/EN/TXT/?uri=CELEX:52016DC0381 (Accessed: 28 April 2018).

European Commission (2016b) Strategic framework - Education \&amp; Training 2020 - European Commission. Available at: http://ec.europa.eu/education/policy/strategic-framework_en (Accessed: 29 April 2018).

Garrison, D. R. and Cleveland-Innes, M. (2005) 'Facilitating Cognitive Presence in Online Learning: Interaction Is Not Enough', American Journal of Distance Education. Lawrence Erlbaum Associates, Inc. , 19(3), pp. 133-148. doi: 10.1207/s15389286ajde1903_2.

Gleason, N. W. (2018) Higher Education in the Era of the Fourth Industrial Revolution, Higher Education in the Era of the Fourth Industrial Revolution. doi: 10.1007/978-981-13-0194-0.

Hacker, D. J. and Niederhauser, D. S. (2000) 'Promoting deep and durable learning in the online classroom', New Directions for Teaching and Learning, 84, pp. 53-63. doi: 10.1002/tl.848.

Harvey, L. (2009) 'A critical analysis of quality culture', in International Network for Quality Assurance Agencies in Higher Education (INQAAHE) Conference, New Approaches to Quality Assurance in the Changing World of Higher Education. Abu Dhabi, United Arab Emirates.

Hay, D. (2007) 'Using concept maps to measure deep, surface and non-learning outcomes', Studies in Higher Education, 32, pp. 39-57. doi: 10.1080/03075070601099432. 
Hernández-Ros, J. (2012) Mainstreaming eLearning in education and training is key / Digital Single Market. Available at: https://ec.europa.eu/digital-single-market/en/blog/mainstreaming-elearning-education-and-training-key (Accessed: 28 April 2018).

Howland, J. L., Jonassen, D. H. and Marra, R. M. (2012) Meaningful Learning with Technology. Pearson. Available at: https://books.google.gr/books?id=EoXPtgAACAAJ.

International Organization for Standardization (2015) 'ISO 9001:2015'.

Jonassen, D. et al. (1995) 'Constructivism and computer-mediated communication in distance education', American Journal of Distance Education. Taylor \& Francis Group, 9(2), pp. 7-26. doi: 10.1080/08923649509526885.

Jonassen, D. H. (2003) Learning to solve problems with technology: a constructivist perspective. Merrill. Available at: https://books.google.gr/books?id=yWzuAAAAMAAJ.

Jordan, K. (2015) 'Massive open online course completion rates revisited: Assessment, length and attrition', The International Review of Research in Open and Distributed Learning; Vol 16, No 3 (2015). Available at: http://www.irrodl.org/index.php/irrodl/article/view/2112/3340.

Koehler, M. J. and Mishra, P. (2009) 'What is Technological Pedagogical Content Knowledge (TPACK)?', Contemporary Issues in Technology and Teacher Education, 9(1), pp. 60-70. doi: 10.1016/j.compedu.2010.07.009.

Lambropoulos, N. et al. (2012) 'Immersive Worlds for Learning eXperience+: Engaging users in the zone of proximal flow in Second Life', in. Paphos, Cyprus, 27 - 28 September, 2012: EADTU Conference. Available at: http://www.projects.eadtu.eu/images/stories/conference/2012/proceedings_06-11-2012.pdf.

Loftus, G. R. (1985) 'Evaluating Forgetting Curves', Journal of Experimental Psychology: Learning, Memory, and Cognition. doi: 10.1037/0278-7393.11.2.397.

Marton, F. and Säljö, R. (1976) ‘On Qualitative Differences in Learning - II Outcome as a Function of the Learner's Conception of the Task', British Journal of Educational Psychology, 46(1947), pp. 115-127. doi: 10.1111/j.20448279.1976.tb02304.x.

Marton, F. and Säljö, R. (1997) 'Approaches to Learning', in The experience of learning, pp. 39-58.

Means, B. et al. (2010) Evaluation of Evidence-Based Practices in Online Learning: A Meta-Analysis and Review of Online Learning Studies., US Department of Education. doi: 10.1016/j.chb.2005.10.002.

Mimirinis, M. and Bhattacharya, M. (2007) 'Design of Virtual Learning Environments for Deep Learning', Journal of Interactive Learning Research, 18(1), pp. 55-64.

Morin, D., Thomas, J. D. E. and Raafat, G. S. (2012) ‘Deep Learning and Virtual Environment', International Journal of Psychological and Behavioral Sciences, 6(11).

Morrison, G. R., Ross, S. M. and Kemp, J. E. (2006) Designing Effective Instruction, Educational Technology Research \& Development. doi: 10.1007/BF02504721.

Mystakidis, S. et al. (2018) 'Towards a Blended Strategy for Quality Distance Education Life-Long Learning Courses - The Patras Model', in Proceedings of the 17th European Conference on e-Learning, ECEL 2018. Athens, Greece.

Mystakidis, S. and Berki, E. (2018) 'The Case of Literacy Motivation: Playful 3D Immersive Learning Environments and Problem-Focused Education for Blended Digital Storytelling', International Journal of Web-Based Learning and Teaching Technologies, 13(1). Available at: https://www.igi-global.com/viewtitlesample.aspx?id=192085.

Mystakidis, S., Berki, E. and Valtanen, J. (2017) 'Designing and Implementing a big Open Online Course by using a 3d Virtual Immersive Environment - lessons learned', in EDULEARN17. Barcelona, 3-5 July 2017, pp. 8070-8079.

OLC (2014) Press Release: Online Learning Survey Report 2014 - OLC. Available at: https://onlinelearningconsortium.org/press-release-online-learning-survey-report-2014/ (Accessed: 29 April 2018).

Ossiannilsson, E. et al. (2015) Quality Models in Online and Open Education around the Globe: State of the Art and Recommendations, Online Submission. Available at: http://elib.tcd.ie/login?url=http://search.ebscohost.com/login.aspx?direct=true\&db=eric\&AN=ED557055\&site=edslive.

Peters, M. A. (2017) 'Technological unemployment: Educating for the fourth industrial revolution', Educational Philosophy and Theory. Routledge, 49(1), pp. 1-6. doi: 10.1080/00131857.2016.1177412.

Project Management Institute (2008) A guide to the project management body of knowledge (PMBOK ${ }^{\circledR}$ guide), Project Management Journal.

Rossi, P. H., Lipsey, M. W. and Freeman, H. E. (2004) Evaluation: A Systematic Approach. SAGE Publications Ltd. doi: 10.1128/AAC.03728-14.

Rothes, A., Lemos, M. S. and Gonçalves, T. (2017) 'Motivational Profiles of Adult Learners', Adult Education Quarterly. SAGE PublicationsSage CA: Los Angeles, CA, 67(1), pp. 3-29. doi: 10.1177/0741713616669588.

Rourke, L. and Kanuka, H. (2009) 'Learning in Communities of Inquiry: A Review of the Literature', Journal of Distance Education. doi: http://dx.doi.org/10.1027/0227-5910.17.4.188.

Schneller, C. and Holmberg, C. (2014) Distance Education in European Higher Education--The Offer. Report 1 (of 3) of the IDEAL (Impact of Distance Education on Adult Learning) Project., UNESCO Institute for Lifelong Learning. UNESCO Institute for Lifelong Learning. Feldbrunnenstrasse 58, 20148 Hamburg, Germany. Tel: +49-40-4480410; Fax: +49-404107723; e-mail: ull-pub@unesco.org; Web site: http://uil.unesco.org. Available at: https://eric.ed.gov/?q=Distance+education+in+European+higher+education\&id=ED560484 (Accessed: 29 April 2018).

Schwab, K. and World Economic Forum (2016) The Fourth Industrial Revolution. World Economic Forum. Available at: https://books.google.gr/books?id=mQQwjwEACAAJ. 
Schwalbe, K. (2015) Information Technology Project Management. Cengage Learning. Available at: https://books.google.gr/books?id=mPeoBAAAQBAJ.

Siemens, G., Gasevic, D. and Dawson, S. (2015) Preparing for the Digital University: A review of the history and current state of distance, blended, and online learning, Athabasca, Canada: Athabasca University. Available at: http://linkresearchlab.org/PreparingDigitalUniversity.pdf.

Steils, N. et al. (2015) 'Implementing the liquid curriculum: the impact of virtual world learning on higher education', Technology, Pedagogy and Education. Routledge, 24(2), pp. 155-170. doi: 10.1080/1475939X.2014.959454.

Stufflebeam, D. L., Madaus, G. F. and Kellaghan, T. (2006) Evaluation Models: Viewpoints on Educational and Human Services Evaluation. Springer Netherlands (Evaluation in Education and Human Services). Available at: https://books.google.gr/books?id=5EAyBwAAQBAJ.

Tyler-Smith, K. (2006) 'Early attrition among first time eLearners: A review of factors that contribute to drop-out, withdrawal and non-completion rates of adult learners undertaking eLearning programmes', Journal of Online learning and Teaching, 2(2), pp. 73-85.

Valtanen, J. et al. (2008) 'Manifold Thinking And Distributed Problem-Based Learning: Is There Potential For ICT Support?', in e-Learning'08, pp. 145-152.

Valtanen, J. et al. (2013) 'Open and Informal Learning in Problem-Focused Higher Education Through Life-Based Design', in Papadourakis, G. (ed.) The 8th International Conference Proceedings New Horizons in Industry, Business and Education. Chania, pp. 15-21.

Vlachopoulos, D. (2016) ‘Assuring Quality in E-Learning Course Design: The Roadmap’, International Review of Research in Open and Distributed Learning, 17(6), pp. 183-205. doi: 10.19173/irrodl.v17i6.2784.

Wenger, E. (1998) 'Communities of Practice: Learning, Meaning, and Identity', Systems thinker, 9, pp. 2-3.

Woo, Y. and Reeves, T. C. (2007) 'Meaningful interaction in web-based learning: A social constructivist interpretation', The Internet and Higher Education. JAI, 10(1), pp. 15-25. doi: 10.1016/J.IHEDUC.2006.10.005.

Yoon, S. (2003) 'In search of meaningful online learning experiences', New Directions for Adult and Continuing Education. John Wiley \& Sons, Ltd, 2003(100), pp. 19-30. doi: 10.1002/ace.116.

Zainuddin, Z. (2018) 'Students' learning performance and perceived motivation in gamified flipped-class instruction', Computers and Education, 126, pp. 75-88. doi: 10.1016/j.compedu.2018.07.003. 